\title{
Cytotoxicity evaluation of self-etching dentine bonding agents in a cell culture perfusion condition
}

Suwanna Korsuwannawong ${ }^{1}$

Ratchaporn Srichan ${ }^{1}$

La-ongthong Vajrabhaya ${ }^{2}$

\section{ABSTRACT}

Objective: The aim of this study was to evaluate the cytotoxicity of three dentine bonding agents (G-Bond, Clearfil S ${ }^{3}$ Bond and Clearfil SE Bond X) in cell-culture perfusion.

Methods: In this experiment, $8 \times 10^{4}$ TCPC SV40 cells (bovine-pulp-derived cells transfected with simian virus 40 large T-antigen) in MEM-alpha media, $20 \% \mathrm{FCS}$ were seeded on mesh in a 6-well plate and incubated at $37{ }^{\circ} \mathrm{C}$ with $5 \% \mathrm{CO}_{2}$. After 2 days, the mesh inserts were transferred to a 24 well plate and incubated in MEM-alpha media, $20 \% \mathrm{FCS}$ with $50 \mu \mathrm{g} / \mathrm{ml}$ of ascorbic acid at $37^{\circ} \mathrm{C}$ with $5 \% \mathrm{CO}_{2}$ for 14 days. The test materials were applied to the dentine discs of dentine barrier models. Three-dimensional cell cultures in mesh and perfusion conditions were generated in this experiment. Each material, as well as the negative control (President) and the positive control (vitrebond), was tested in 5 models with the tests repeated in triplicate. The MTT assay was used to determine cell viability after the diffusion of leachable toxicity from the tested materials through the dentine discs.

Results: The cell survival rate with G-Bond and Clearfil S3 Bond was 113.03 and 90.98 percent, respectively, whereas that with Clearfil SE Bond X was 111.83 percent. All three dentine bonding agents had no toxicity compared with the negative control group $(P>05)$.

Conclusions: All three self-etching dentine-bonding agents are nontoxic. Pulp damage caused by these three bonding agents is unlikely to occur in the clinic. (Eur J Dent 2012;6:408-414)

Key words: Cytotoxicity; MTT assay; perfusion condition; three-dimensional cell cultures

- 1 Research Service Center, Faculty of Dentistry, Mahidol University, Yothi Street, Rachatavee, Bangkok, 10400 THAILAND

2 Faculty of Dental Medicine, Rangsit University, Muang-Ake, Phaholyothin Road, Lak-Hok, Patumthani 12000 THAILAND

- Corresponding author: Suwanna Korsuwannawong Research Service Center, Faculty of Dentistry, Mahidol University, Yothi Street, Bangkok, 10400 THAILAND Tel: +6626607755 ext. 7756-7757 Fax: +66 23548510 E-mail: dtsat@mahidol.ac.th

\section{INTRODUCTION}

Dentine bonding agents are bonding agents that consist of 3 parts: (i) an acid that removes the smear layer accumulated on the dentine and that helps increase the microporosity of the enamel (etching step), (ii) a substance that enhances the flow of bonding agents into the dentine and increasing the microporosity of the enamel by modifying dentine as a bonding substrate (priming step), and (iii) 
the bonding agents (bonding step). Traditionally, the use of dentine bonding agents required the use of all three of these steps. Recently, however, dentine bonding agents have been developed that reduce the process to only one or two steps, resulting in faster and more convenient application. Selection of a dentine bonding agent requires the consideration of the bonding properties (i.e., how effectively the bonding agent can bond the dental restorative material to the dentine) and the cytotoxicity of the dentine bonding agents. ${ }^{1-2}$

In a previous study, the cytotoxicity of three dentine bonding agents was determined using the agar overlay technique. ${ }^{3}$ The results showed that the toxicity of G-Bond and Clearfil $\mathrm{S}^{3}$ Bond diffusing into the agar medium was moderate whereas that of Clearfil SE Bond X was high. The study also found that the three dentine bonding agents yielded the same lysis index (i.e., 1). This result revealed that the three dentine bonding agents have low toxicity according to the ISO/FDIS 7405:2008 (E) Standard, which is based on an in vitro evaluation of the biocompatibility of medical devices used in dentistry. ${ }^{4}$ However, the agar overlay technique only allowed a preliminary cytotoxicity evaluation and did not reveal the percentage of surviving cells. The results only indicated the cytotoxicity of the tested dentine bonding agents.

It is advisable to evaluate the biological properties of dentine bonding agents that are in close contact with dentine prior to using them in patients. According to the ISO 7405:1997 Standard, an in vitro evaluation of the biological properties of dentine bonding agents (e.g., cytotoxicity evaluation through a cell-culture test) is the primary method used to evaluate the cytotoxicity of such agents. ${ }^{5}$ Originally, researchers used cell-culture tests to evaluate the biological properties of dental materials. ${ }^{6}$ The agar overlay method and the Millipore filter method were introduced to simulate the material-cell contact interaction. ${ }^{7-8}$ However, the agar and filter methods still did not simulate dentine in vivo clinically. In 1977, the model cavity system was introduced to better simulate the clinical situation. ${ }^{9}$ The test material was separated from the cells by either a synthetic filter or a dentine slice. Most subsequent in vitro models were based on the use of human dentine. An in vitro test system using dentine for the evaluation of toxicity has been reported..$^{10-12}$ In these studies, the toxic products of materials that diffused through the dentine were diluted in at least $2.5 \mathrm{ml}$ of cell culture medium before contacting the target cells. However, in a clinical situation, the leachable toxic product will have a direct effect on the cells of the pulp, which lie close to the dentine.

In 1996, a dentine barrier model for the cytotoxicity evaluation of dental cement was reported. ${ }^{13}$ This model is based on a commercially available device and is considered to be an important prerequisite for a standard test. In this model, the cells were seeded on the pulp side of the dentine and were placed above the cell culture medium. This in vitro pulp chamber simulated in vivo conditions. Our study used a dentine model and threedimensional cell cultures that have been previously described by Ulker and Sengun. ${ }^{14}$

Cell perfusion was limited by the blood circulation inside the tooth cavity and was equal to $20-82.4 \mathrm{ml} / \mathrm{min} / 100$ grams of tissue. ${ }^{15}$ It has been reported that perfusing the chamber with $5 \mathrm{ml}$ medium/h did not decrease toxicity but can lead to increased cell death or cell disruption. ${ }^{16}$ Therefore, in the present study, the perfusion conditions included a cell feed flow rate of $2.0 \mathrm{~mL} / \mathrm{h}$. At this flow rate, cells have a higher survival rate than those cultured under static conditions. This difference may be because this rate mimics the blood flow within the pulp chamber, where cytotoxic leaching occurs.

The aim of this study was to evaluate the cytotoxicity of three self-etching dentine-bonding agents ( $G$ Bond, Clearfil $S^{3}$ Bond and Clearfil SE Bond XI with a three-dimensional cell culture and perfusion conditions that were not used in the previous study. ${ }^{3}$ The hypothesis tested was that different self-etching dentine bonding agents have different cytotoxic profiles.

\section{MATERIALS AND METHODS}

Test materials

Three self-etching dentine bonding agents were used in this study. $G$ Bond, Clearfil $S^{3}$ Bond and Clearfil SE Bond X were the experimental materials. The negative and positive controls were President (Coltene AG, Alstatten, Switzerland) and Vitrebond (3M Medica GmbH, Germany), respectively. Material compositions, manufacturers and batch numbers are shown in Table 1. 


\section{Mesh preparation}

Polyamide (diameter $8 \mathrm{~mm}$ ) was etched with $0.1 \mathrm{M}$ acetic acid for $30 \mathrm{~min}$, washed with sterile water 3 times and sterilized by autoclaving ( $\mathrm{Hi}-$ rayama, Tokyo, Japan) before the experiment. The mesh was coated in fibronectin $10.03 \mathrm{mg} / \mathrm{ml}$ in water), and the mesh was left to dry for $2 \mathrm{~h}$ in a biohazard safety cabinet.

\section{Cell preparation}

The target cells used in this experiment were TCPC SV40 lbovine fibroblast pulp-derived cells transfected with simian virus 40 large T-antigen). ${ }^{16}$ A $1.25-\mathrm{ml}$ volume of MEM-alpha (Minimum Essential Media, Gibco, New York, USA), including $20 \%$ fetal calf serum, was added to each well of a 6-well tissue culture plate. Then, a Millicell membrane (Minucells and Minutissue, Bad Abbach, Germany; size $30 \mathrm{~mm}$, pore size $0.45 \mu \mathrm{m}$ ) was inserted in each well.

Four dried meshes were placed in each insert. A $20-\mu \mathrm{l}$ aliquot containing $4 \times 10^{6}$ cells $/ \mathrm{mL}$ was dropped on each mesh in the insert. The plate was incubated at $37^{\circ} \mathrm{C}$ with $5 \% \mathrm{CO}_{2}$ and $100 \%$ humidity for $48 \mathrm{~h}$. Then, each mesh was separately placed into the wells of a 24-well tissue culture plate. The cells on the meshes were fed with $1 \mathrm{ml}$ of MEM-alpha media, $20 \%$ FCS containing $50 \mu \mathrm{g} / \mathrm{ml}$ of ascor-
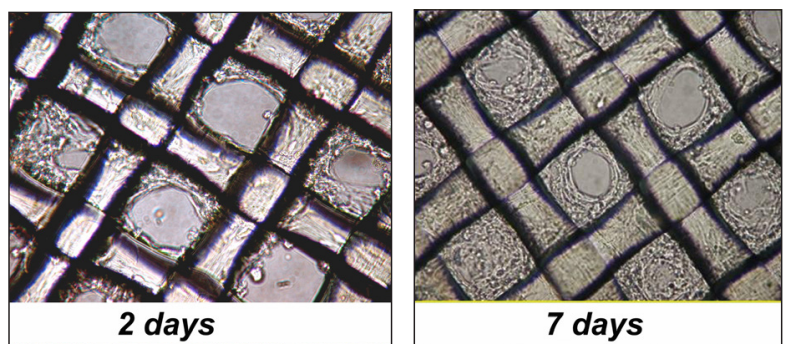

7 days bic acid, and the medium was changed every other day. After growing for 14 days in the incubator, the three-dimensional cell cultures on the meshes were ready for use in the experiment (Figure 1).

\section{Dentine disc preparation}

A dentine disc that was $500 \pm 25 \mu \mathrm{m}$ thick and that was close to the pulp cavity was longitudinally sectioned from a bovine incisor. A dentine disc with a diameter of 6-7 mm under the cementoenamel junction was cut for the experiment. The pulp side of each disc was etched with $50 \%$ citric acid for 30 $\mathrm{s}$, soaked in normal saline and autoclaved before the experiment (Figure 2).

\section{In vitro perfusion chamber}

A commercial cell culture chamber (Minucells and Minutissue, Bad Abbach, Germanyl was used for the in vitro model. ${ }^{16}$ The chamber was separated into a pulp side and a cavity side by the dentine disc mentioned above. The pulp side of the disc was placed over the cultivated cell mesh, and a stainless steel clamp held the 2 compartments together. Cells in the mesh were fed with MEMalpha media, $20 \%$ FCS that was contained in the lower part of the chamber. The model was placed on a hot plate $\left(37 \pm 2{ }^{\circ} \mathrm{C}\right)$, and culture medium was perfused through the lower part of the chamber. Each dentine bonding agent as well as the nega-
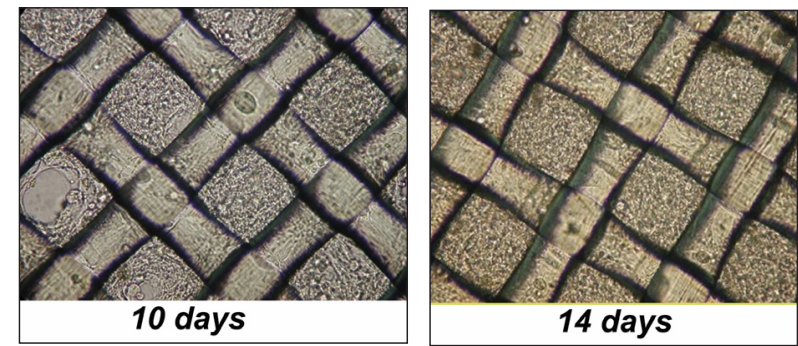

Figure 1. Cell culture on mesh after incubation for 2 days, 7 days, 10 days and 14 days, observed using an inverted microscope. (Mag. 10x).

Table 1. Material composition, manufacturers and batch numbers.

\begin{tabular}{|c|c|c|c|}
\hline Material & Manufacturer & Composition & Batch \# \\
\hline G-Bond ${ }^{\mathrm{TM}}$ & GC Corp, Tokyo, Japan & $\begin{array}{l}\text { 4-MET monomer, Phosphoric acid, Acetone, Water, } \\
\text { UDMA, Silica }\end{array}$ & 603291 \\
\hline Clearfil ${ }^{T M} S^{3}$ Bond $d^{T M}$ & $\begin{array}{l}\text { Kuraray Medical Inc, Okayama, } \\
\text { Japan }\end{array}$ & $\begin{array}{l}\text { MDP, Bis-GMA, HEMA, Hydrophobic dimethacrylate, } \\
\text { Di-camphorquinone, Ethyl alcohol, Water, Silanated } \\
\text { colloidal silica, Hydrophilic monomer }\end{array}$ & $00045 \mathrm{~A}$ \\
\hline Clearfil $^{\mathrm{TM}}$ SE Bond ${ }^{\mathrm{TM}} X$ & $\begin{array}{l}\text { Kuraray Medical Inc, Okayama, } \\
\text { Japan }\end{array}$ & $\begin{array}{c}\text { Primer: MDP, HEMA, Di-camphorquinone, Water } \\
\text { Bonding: Bis-GMA, MDP, HEMA, Di-camphorquinone, } \\
\text { Silanated colloidal silica }\end{array}$ & $\begin{array}{l}00603 \text { A (Primer) } \\
00852 \text { A (Bonding) }\end{array}$ \\
\hline $\begin{array}{l}\text { President } \\
\text { (Negative Control) }\end{array}$ & Silicone impression material & Coltene AG, Alstatten, Switzerland & MJ938 \\
\hline $\begin{array}{l}\text { Vitrebond } \\
\text { (Positive Control) }\end{array}$ & $\begin{array}{c}\text { Light-curing glass lonomer ce- } \\
\text { ment }\end{array}$ & 3M Medica GmbH, Broken, Germany & 20040517 \\
\hline
\end{tabular}


tive and positive control was tested in 5 cell culture chambers. All experiments were repeated in triplicate. The perfusion pump (Ismatec UK Co. Weston-super-Mare, England) was connected and adjusted to a perfusion rate of $0.2 \mathrm{ml} / \mathrm{h}$ for $24 \mathrm{~h}$ before application of the test material (Figure 3 ). A cotton pellet soaked with culture medium was placed on the dentine of the cavity side.

\section{The test procedure}

After $24 \mathrm{~h}$ of perfusion, the perfusion rate of the medium was adjusted to $2 \mathrm{ml} / \mathrm{h}$ to simulate blood flow in the pulp. The cotton pellet in the cavity side was removed. The dentine in the cavity side was cleaned with sterile water and dried with gently blown air. Three self-etching bonding agents as well as the President and Vitrebond controls were applied to the dentine according to the manufacturers' recommendations. The enzymatic activity of target cells was analyzed using the MTT

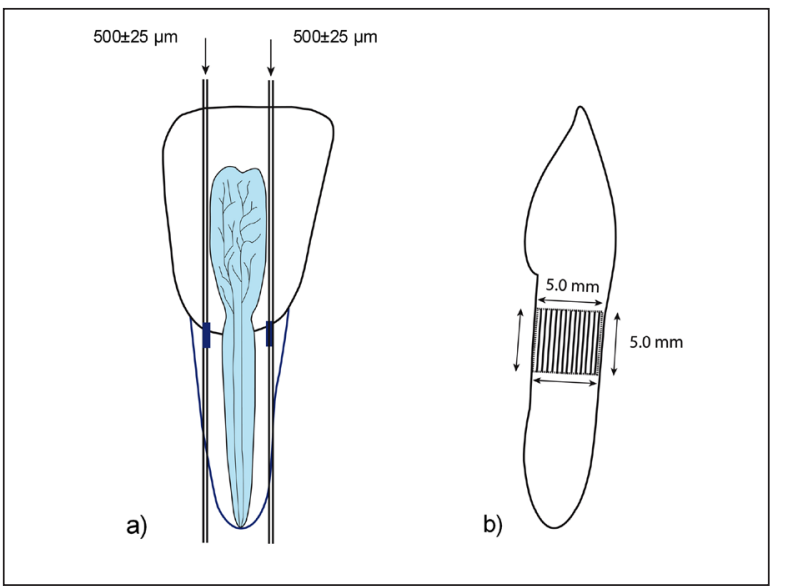

Figure 2. Schematic illustration of the bovine tooth dentine slices (a) Longitudinal section of $500 \pm 25 \mu \mathrm{m}$ thickness

(b) $5 \times 5 \mathrm{~mm}^{2}$ section at the level of the cemento-enamel junction

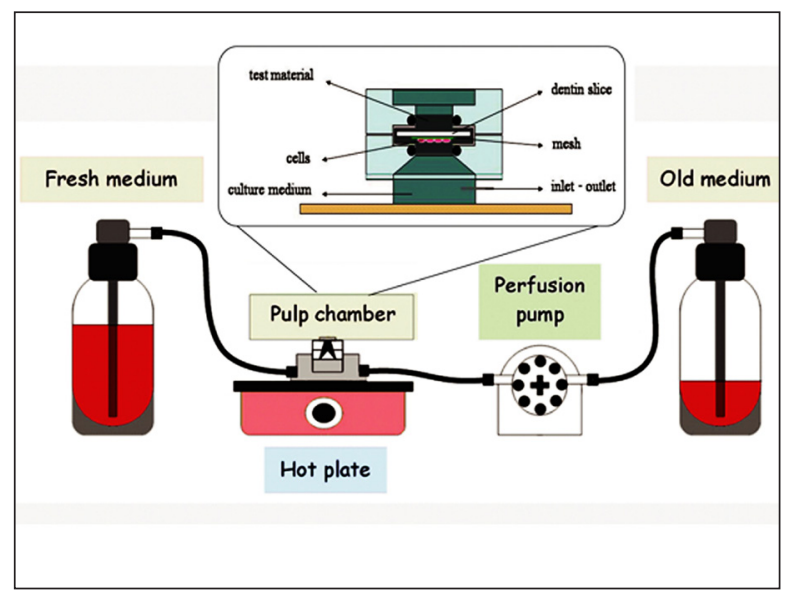

Figure 3. Perfusion conditions. (3-(4,5-dimethylthiazol-2-yl)-2, 5-diphenyl tetrazolium bromide) assay after $24 \mathrm{~h}$ of test material exposure.

\section{MTT assay}

The mesh was removed from the stainlesssteel holder of the perfusion chamber and immediately inserted into $0.5 \mathrm{ml}$ of freshly prepared MTT solution (1 well/1 mesh) in a 48-well tissue culture plate. The plates were incubated for $2 \mathrm{~h}$. Mitochondrial dehydrogenase in living cells converts the yellow water-soluble tetrazolium salt 3-14, 5-dimethylthiazol-2-yl)-2, 5 -diphenyltetrazolium bromide into dark blue formazan crystals that are stored in the cytoplasm of the cells. Then, the MTT solution was removed, and the mesh was washed twice with $0.5 \mathrm{ml}$ of phosphate-buffered saline solution. Dimethyl sulfoxide (DMSO; $250 \mu \mathrm{l}$ ) was added to each well to dissolve the formazan. The plate was agitated on a shaker for 30 minutes to enhance the dissolution of the formazan. A 200- $\mu \mathrm{l}$ aliquot was drawn from each well and transferred to a 96-well tissue culture plate. The spectrophotometric absorbance was measured at $540 \mathrm{~nm}$, using DMSO as the blank.

\section{Statistical analysis}

The mean optical density of the negative control group was set to represent $100 \%$ viability. The results for the experimental groups and the positive control were expressed as the percentages of the negative control. The statistical analysis was performed by applying the non-parametric MannWhitney test $(P<.05)$.

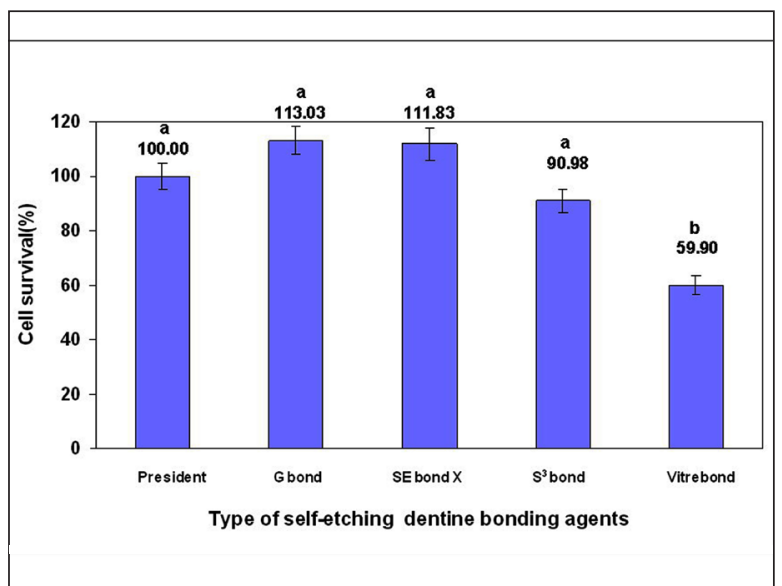

Figure 4. Cell viability percentages after testing with self-etching dentine bonding agents, positive controls and negative controls. (different superscript letters signify $P<.05)$ 


\section{RESULTS}

The percentages of viable cells compared to the controls for $G$ Bond, Clearfil SE Bond $X$ and Clearfil $S^{3}$ Bond are shown in Figure 4. The average percent cell viability after exposure to $G$ Bond, Clearfil SE Bond X, Clearfil S ${ }^{3}$ Bond and Vitrebond was $113.03,111.83,90.98$ and 59.90 , respectively. Vitrebond was more toxic than $G$ Bond, Clearfil SE Bond $X$ and Clearfil $S^{3}$ Bond $(P<.01)$, whereas the experimental group did not have any toxicity compared with the negative control group $(P>05)$.

\section{DISCUSSION}

In a previous study, the cytotoxicity levels of self-etching dentine-bonding agents $(G$ Bond, Clearfil SE Bond $X$ and Clearfil $S^{3}$ Bond) were evaluated using the agar overlay technique. This analysis showed that the $\mathrm{G}$ Bond and Clearfil $\mathrm{S}^{3}$ Bond were both moderately cytotoxic, whereas the Clearfil SE Bond X appeared to be more toxic than the other 2 bonding agents. The amount of cells destroyed by each of the three dentine bonding agents was not significantly different. ${ }^{3}$ Because this was only a preliminary evaluation of the cytotoxicity of the three dentine-bonding agents, it was not possible to determine the level of toxicity quantitatively. Hence, a qualitative study of a dentine barrier model simulating clinical practice was needed to obtain reliable data. This study revealed that the percent of viable cells for $G$ Bond, Clearfil $\mathrm{S}^{3}$ Bond and Clearfil SE Bond X was 113.03, 90.98 and 111.83 , respectively.

In this study, three dentine bonding agents were studied under two systems. G-Bond and Clearfil $\mathrm{S}^{3}$ Bond were processed in one step, and a twostep system was used for the self-etching primer bonding system of Clearfil SE Bond X. In the allin-one system, the etching, priming and bonding steps are combined together as one step for resinbonding. In contrast, in the two-step self-etching primer bonding system, the etching and primer steps are combined together as a single step that is separate from applying the resin bonding agent prior to restoration of the tooth with a resin composite. In the Clearfil $\mathrm{S}^{3}$ Bond experiment, cell viability was $90.98 \%$. This value was lower than the other groups, but the difference was not statistically significant. The difference may be due to the presence of hydrophobic dimethacrylate in the composition. Hydrophilic monomers such as
HEMA or TEGDMA have been shown to be cytotoxic, but to a lesser degree than a more hydrophobic monomer. ${ }^{17}$ However, self-etching adhesive systems were less cytotoxic than the total-etching system. ${ }^{18}$

The preparation of materials for experiments significantly has been reported to alter the apparent cytotoxicity of the materials. ${ }^{19}$ Thus, every effort was made to simulate in vivo conditions in the laboratory. However, it is not possible to create an environment that totally replicates clinical conditions. Cell toxicity assays have been performed both in cell lines and primary cells, but immortalized cell lines are more stable than primary cells. ${ }^{20}$

No differences have been observed in the growth of bovine pulp-derived cell lines transfected with simian virus that were seeded on dentine discs and those seeded on tissue culture plates. ${ }^{21}$ Scanning electron microscopy (SEM) also showed biocompatibility between the dentine and cells. Thus, bovine teeth are an appropriate choice for use with the bovine pulp cell line in this experiment.

It has been demonstrated that $0.5 \mathrm{~mm}$ of dentine can reduce material toxicity to $75 \%$ and that $1 \mathrm{~mm}$ of dentine can reduce toxicity by up to $90 \%$ of the control value (i.e., the value obtained when dentine was not present). ${ }^{22}$ Most cytotoxicity research uses $500 \mu \mathrm{m}$ for the standard thickness of the dentine barrier slice in the pulp chamber model. ${ }^{23}$ The permeability of the dentine varies in different regions of the tooth. Therefore, the region of dentine that is selected is important when evaluating restorative materials in terms of bond strength and cytotoxicity. Maroli et al ${ }^{24}$ showed, using scanning electron micrographs, that there are more tubular openings in the cervical third of approximal sections than in occlusal and middle. The cervical area of the bovine tooth was used as the dentine barrier in this experiment. With respect to transdentine permeability characteristics, bovine dentine at the level of the cemento-enamel junction seems to be a suitable alternative for coronal human dentine..$^{25}$

The use of perfused dentine barrier models is a widely accepted method of evaluating the biological properties and the toxicity of dental restorative materials that will come into contact with dentine. However, each step of these experiments must be performed cautiously. If contamination occurs 
during the experiment, the experiment will be ineffective because the complete growth of the cell culture in the mesh requires 14 days. Moreover, researchers must have adequate experience with and knowledge of 3-D cell culture techniques. Each step requires meticulous technique, especially the installation of the perfusion system, which is a 3-way connection with a flow rate similar to blood flow in the actual pulp. The results from such experiments are similar to clinical conditions and are reliable. Another advantage of this study was the ability to reduce the quantity and frequency of animals used in experiments. An experiment with animals is needed when the results from of in vitro studies are ambiguous. In accordance with the first priority of ISO 7405, it is recommended to avoid the use of animals for experiments if the study can possibly be conducted in vitro.

\section{CONCLUSION}

All three self-etching dentine-bonding agents were non-toxic compared with the negative control group $(P>$.05). These agents could be used clinically in cases where there is more than $.5 \mathrm{~mm}$ of remaining dentine above the pulp.

\section{ACKNOWLEDGMENTS}

The authors would like to thank Professor Dr. Gottfried Schmalz (Regensburg University, Germanyl for supplying the target cells used in this experiment (TCPC SV40, bovine fibroblast pulpderived cells transfected with simian virus 40 large T-antigen). This study was supported by a Mahidol University Grant.

\section{REFERENCES}

1. 1. Ferracane JL. Materials in dentistry principles and application. J.B. Lippincott Company; 1995. 1.

2. O,Brien WJ. Dental materials and their selection. $2^{\text {nd }}$ ed. Quintessence Publishing Co. Inc.;1997.

3. Korsuwannawong S, Srichan R, Vajrabhaya L. Cytotoxicity evaluation of dentine bonding agents : Agar overlay technique. J Dent Assoc Thai 2008;58:196-203.

4. ISO Standards/FDIS. Evaluation of biocompatibility of medical devices used in dentistry. International Organization for Standardization $2^{\text {nd }}$ edition.ISO 7405; 2008(E):1-23.

5. ISO Standards. Preclinical evaluation of biocompatibility of medical devices used in dentistry. International Organization for Standardization $1^{\text {st }}$ edition. ISO 7405 Dentistry; 1997:118.
6. Kawahara H, Yamagami A, Nakamura Jr. Biological testing of dental materials by means of tissue culture. Int Dent $J$ 1968:18:443-467.

7. Schmalz G. A reproducibility study on the agar diffusion test. J. Dent Res 1982;61:577-580.

8. Wennberg A. In vitro assessment of the biocompatibility of dental material-the Millipore filter method. Int Endod $J$ 1988;21:67-71.

9. Tyas MJ. A method for the in vitro toxicity testing of dental restorative materials. J Dent Res 1977;56:1285-1290.

10. Meryon SD. The model cavity method incorporating dentine. Int Endod $J$ 1988;21:79-84.

11. Hume WR. A new technique for screening chemical toxicity to the pulp from dental restorative materials and procedure. J Dent Res 1985;64:1322-1325.

12. Hanks CT, Craig RG, Diehl ML, Pashley DH. Cytotoxicity of dental composites and other materials in a new in vitro device. J Oral Pathol 1988;17:396-403.

13. Schmalz G, Garhammer P, Schweilkl H. A commercially available cell culture device modified for dentine barrier tests. J Endod 1996;22:249-52.

14. Ulker HE, Sengun A. Cytotoxicity evaluation of self adhesive composite resin cements by dentin barrier test on 3D pulp cells. Eur J Dent 2009;3:120-126.

15. Matthews B, Andrew D. Microvascular architecture and exchange in teeth. Microcirculation. 1955;2:305-313.

16. Schmalz G, Schuster U, Nuetzel K, Schweikl H. An in vitro pulp chamber with three dimensional cell cultures. $J$ Endod $1999 ; 25: 24-29$.

17. Ratanasathien S, Wataha JC, Hanks CT, Dennison JB. Cytotoxic interactive effects of dentin bonding components on mouse fibroblasts. J Dent Res. 1995;74:1602-1606.

18. Koulaouzidou EA, Helvatjoglu - Antoniades M, Palaghias G, Karanika - Kouma A, Antoniades D. Cytotoxicity of Dental Adhesives in vitro. Eur J Dent 2009;3: 3-9.

19. Spangberg L, Pascon EA. The importance of material preparation for the expression of cytotoxicity during in vitro evaluation of biomaterials. J Endod 1988;14:247-250.

20. Thonemann B, Schmalz G, Esterbauer S, Schuster U, Schweikl H. Growth kinetics of Bovine Pulp Cell line on dentin. $J$ Dent Res 1997;78:514.

21. Slivka SR, Landeen LK, Zeigler F, Zimber MP, Bartel RL. Characterization,barrier function, and grug metabolism of an in vitro skin model. J Invest Dermatol 1993;100:40-46.

22. Meryon SD, Jakman KJ. Aluminum and dental materials: A study in vitro of its potential release and cytotoxicity. Int Endod $J 1987 ; 20: 16-19$.

23. Stanley HR, Going RE, Chauncey HH. Human pulp response to acid pretreatment of dentine and to composite restoration. J Am Dent Assoc 1975;91:817-825. 
24. Maroli S, Khera SC, Krell KV. Regional variation in permeability of young Dentin. Oper Dent 1992;17:93-100.

25. Schmalz G, Hiller KA, Nunez Lz, Stoll J, Weis K. Permeability characteristics of bovine and human dentine under different pretreatment conditions. $J$ Endod 2001;27:23-30. 